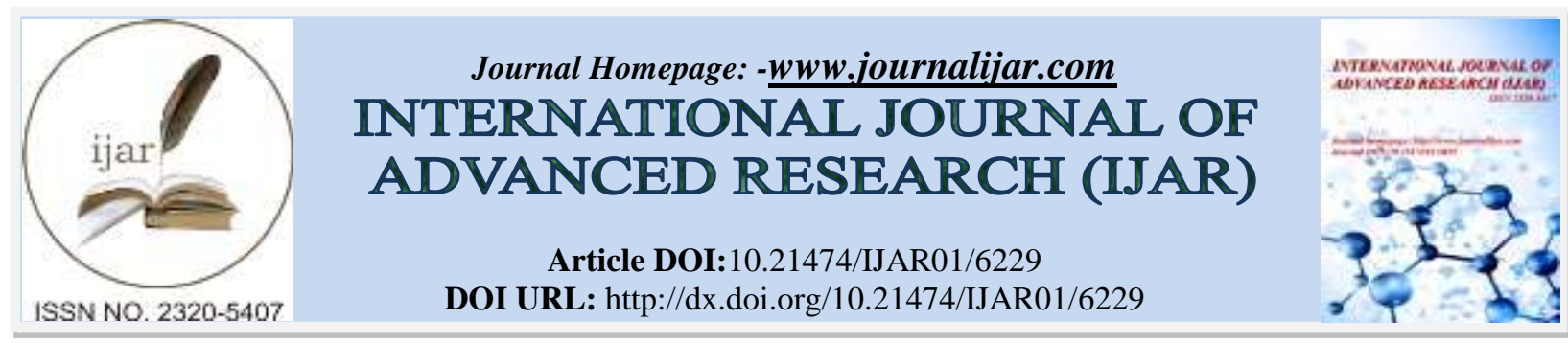

RESEARCH ARTICLE

\title{
COMPARISION OF SERUM AND SALIVA COTININE LEVELS AMONG SMOKERS AND NON SMOKERS BY USING ELISA.
}

\section{Rajesh. A ${ }^{1}$, Jayavardhini. $P^{1}$, Prasanth. $T^{2}$, Praveen Kumar $M^{1}$, Syed Rahamathulla ${ }^{3}$, Aruna. $D^{1}$ and Sufia sultana ${ }^{4}$.}

1. Dept. Of oral pathology, cks theja institute of dental sciences and research, chadalwadanagar, renigunta road, tirupathi-517506.

2. Dept. Of oral pathology, sreemookambia institute of dental sciences, kulasekharam, kanyakumari-629161

3. Director of pathgene health care private limited, tiruchanoor road, tirupathi-517503.

4. Sri Padmavati mahila viswa vidayalam, padmavathi nagar, tirupathi-517502.

\section{Manuscript Info}

\section{Manuscript History}

Received: 05 November 2017

Final Accepted: 07 December 2017

Published: January 2018

Key words:-

Cotinine,Serum,Saliva,ELISA.

\begin{abstract}
Background: Cotinine, important metabolite of nicotine, is a biomarker for monitoring tobacco exposure from both active smoking and passive smoking. The current study aimed to estimate the cotinine levels and compare the association between serum cotinine and salivary cotinine among smokers and non smokers. Methods: Consecutive consenting individuals $(n=50)$ of 25 smokers (group I) \& 25 non smokers (group II) with an age range of 21-75 yrs and with no apparent systemic illness were included in the study and detailed history of smoking was recorded. Serum and unstimulated saliva were collected from each subject in a separate plastic vials and cotinine levels were analyzed using Enzyme-linked immunosorbent assay (ELISA). Results: Among smokers $96 \%$ positivity for cotinine was shown in serum \& $100 \%$ in saliva samples. Among non smokers $40 \%$ positivity for cotinine was shown in serum \& $80 \%$ in saliva samples. When both groups were compared, cotinine positivity was slightly higher in saliva than serum. The results showed cotinine detection was more sensitive in saliva than serum samples. Conclusion: Saliva, being more accessible and noninvasive than serum, it can be used as an alternative diagnostic aid for detection of cotinine mainly for epidemiological surveys and patient education.
\end{abstract}

Copy Right, IJAR, 2018,. All rights reserved.

\section{Introduction:-}

Smoking has been linked with many deleterious effects on human health (Florescu A et al., 2009). The lack in the development of valid and precise method for measurement of exposure to smoking and its associated health risks constitute a dynamic area of research in the present era. Biomarkers are the most frequently used for ascertaining tobacco exposure. Nicotine was formerly considered as a definite biomarker as it is an important biologically active ingredient of tobacco. Nicotine biomarker assay is more sensitive due to its shorter plasma half life and presence of relatively low concentrations in the blood and urine among active and passive smokers (Kyerematenet al., 1990). 
Cotinine is an alkaloid and the major metabolite of nicotine; it can be used as an index for exposure to tobacco smoke and Environmental tobacco smoke (ETS) as majority (72\%) of nicotine is transformed to cotinine (Benowitz NL, 1996; Benowitz NL et al., 2009). The cotinine plasma half-life is estimated to be nearly 15-20 hours where as nicotine half-life is no more than 0.5-3 hours (Jarvis MJ et al., 1988). Due to its significantly longer half-life, cotinine biomarker is more often preferred than nicotine for the measurement in blood serum, urine, semen, hair and saliva. The half-life of cotinine in serum and saliva is approximately the same (Benowitz NL, 2009; Kunzle R et al., 2003; AL-Delaimy WK, 2002).

To study a disease process associated with smoking, saliva is considered as important diagnostic tool. In addition, to the investigation of saliva for exposure of tobacco smoke, it also provides vital information regarding the functioning of a variety of organs and endocrine system inside the body. With respect to epidemiological approach saliva is quite stable at surrounding temperature which in assays saliva provides a newer instrumentation (Chiappin S et al., 2007). Studies also suggested that saliva cotinine estimation can be future alternative to serum, although serum is more sensitive to early changes in smoking status than saliva cotinine (Haley NJ et al., 1983; Sepkovic DW et al., 1985). Other methods proposed for the assessment of cotinine levels in biological matrices includes gas (GC) and liquid (LC) chromatography to observe the exposure in tobacco smokers (Jacob P et al., 1992; Malafatti L et al., 2010). Due to expensive cost of equipment, sampling methods and expertise in the field, GC and LC are not always suitable for the evaluation of cotinine levels (Jacob P et al., 1992; Matsumoto A et al., 2010). ELISA is an alternative procedure for a larger sample size where samples are analyzed rapidly or when suitable chromatographic equipment is unavailable. Reports suggest that immunoassays are more advantageous for comparative values than analytical equipment systems (Szumska M et al., 2013; Matsumoto A et al., 2010; Benkirane S et al., 1991).

Cotinine has a smaller molecular size, negligible protein binding in blood and relatively water soluble with a concentration of $15 \%$ to $40 \%$ more in saliva than serum (Avila-Tang Eet al., 2012). Thus cotinine measurement in saliva becomes an easy, non invasive method of estimation for larger samples in a limited time period (Avila-Tang Eet al., 2012; Wall AM et al., 1998; Nosratzehi T et al., 2015).

To maintain uniformity in the method of sample collection and storage, some researchers have an inclination to use unstimulated, whole saliva that pools on the floor of the mouth (Granger AD et al., 2007). Considering this background, the aim of this study is to estimate the cotinine levels and compare the association between serum cotinine and salivary cotinine among smokers and non smokers.

\section{Materials and Methods:-}

A total of 50 individuals in our locality (Tirupathi) were enrolled. The subjects were equally divided into two groups consisting of 25 smokers (group I) \& 25 non smokers (group II) with an age range of 21-75 yrs and with no apparent systemic illness were included in the study and detailed history of smoking was recorded. Written informed consent was obtained from all the subjects who were enrolled for the study. Among smokers 25 males who smoked two to fifty cigarettes per day were enrolled \& among 25 nonsmokers; 21 were males and 4 females, who did not smoke but either lived with a smoker or worked in an office or ward where smoking was allowed. Ethical clearance was obtained \&both serum and unstimulated saliva samples were collected from each individual and subjected to cotinine analysis by ELISA. The serum samples from venipuncture and unstimulated whole saliva samples were collected from each group in two separate vials, labeled \&immediately frozen at $-20^{\circ} \mathrm{C}$ until further evaluation of cotinine by ELISA was done by using the respective kits (serum cotinine- KRISH LIFE:9001 and saliva cotinineSALIMETRICS:2112). Saliva cotinine values $>0.1 \mathrm{ng} / \mathrm{mL}$ and serum cotinine values $>1 \mathrm{ng} / \mathrm{mL}$ were labeled as positive for cotinine.

\section{Results:-}

The study included 50 subjects which were divided into two groups. The mean age of nonsmokers was $47.24 \pm 10.50$ (27-71) years, and the smoker's was 52.68 \pm 12.52 (26-73) years (Fig 1). Among smokers, 24 (96\%) samples were positive for cotinine in serum and all the 25 (100\%) samples were positive for saliva (Fig 2). Among non-smokers 10 samples were positive for serum whereas 20 samples were positive for saliva (Fig 3). Comparison of serum and salivary cotinine was done using Two-way ANOVA test. When both the groups were compared smokers showed increase in serum and salivary cotinine levels than non smokers and was statistically significant ( $<<0.001)($ Fig 4$)$. 


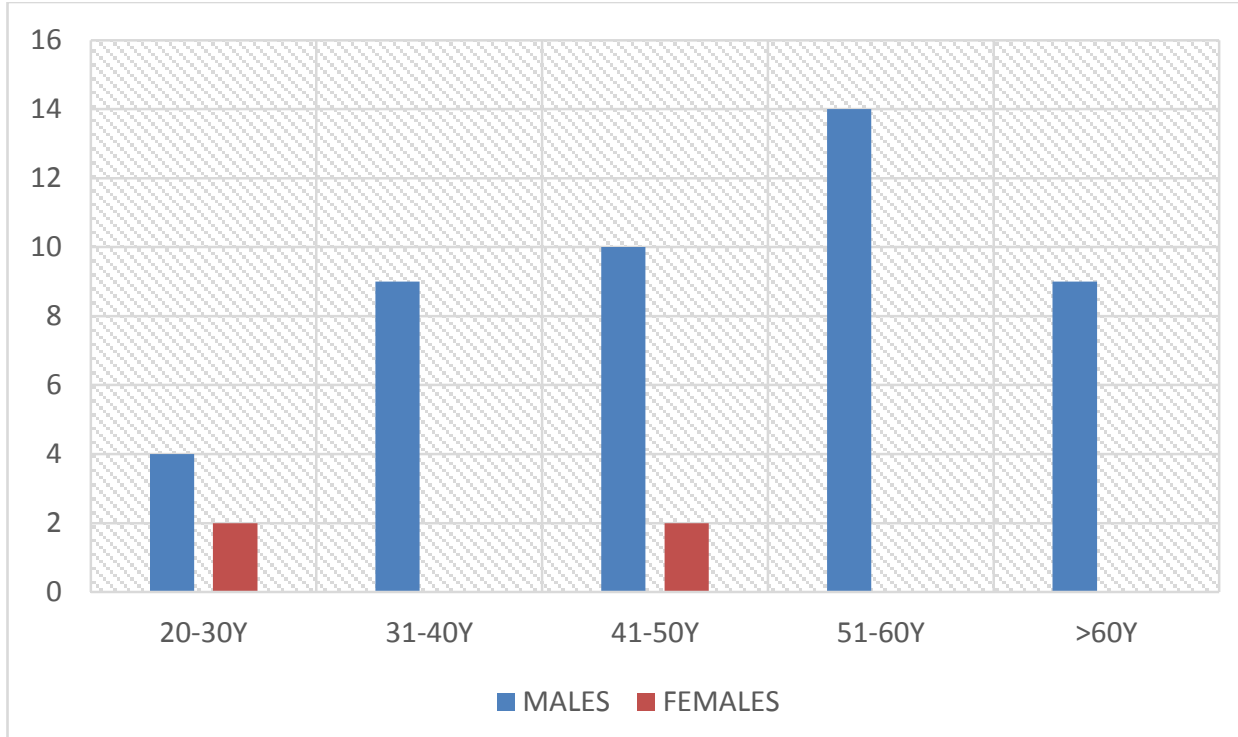

Fig 1:-Age wise distribution among smokers and non smokers

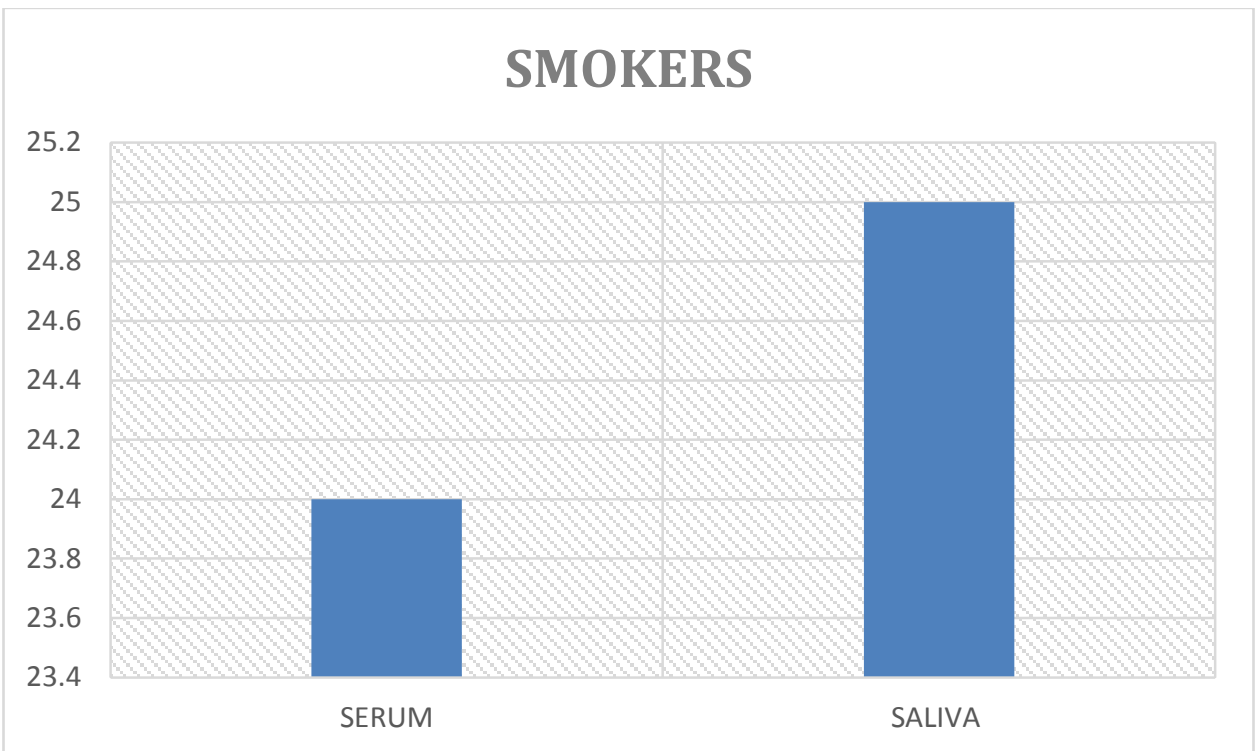

Fig 2:-Comparison of Serum and Saliva cotinine positive subjects in Smokers 


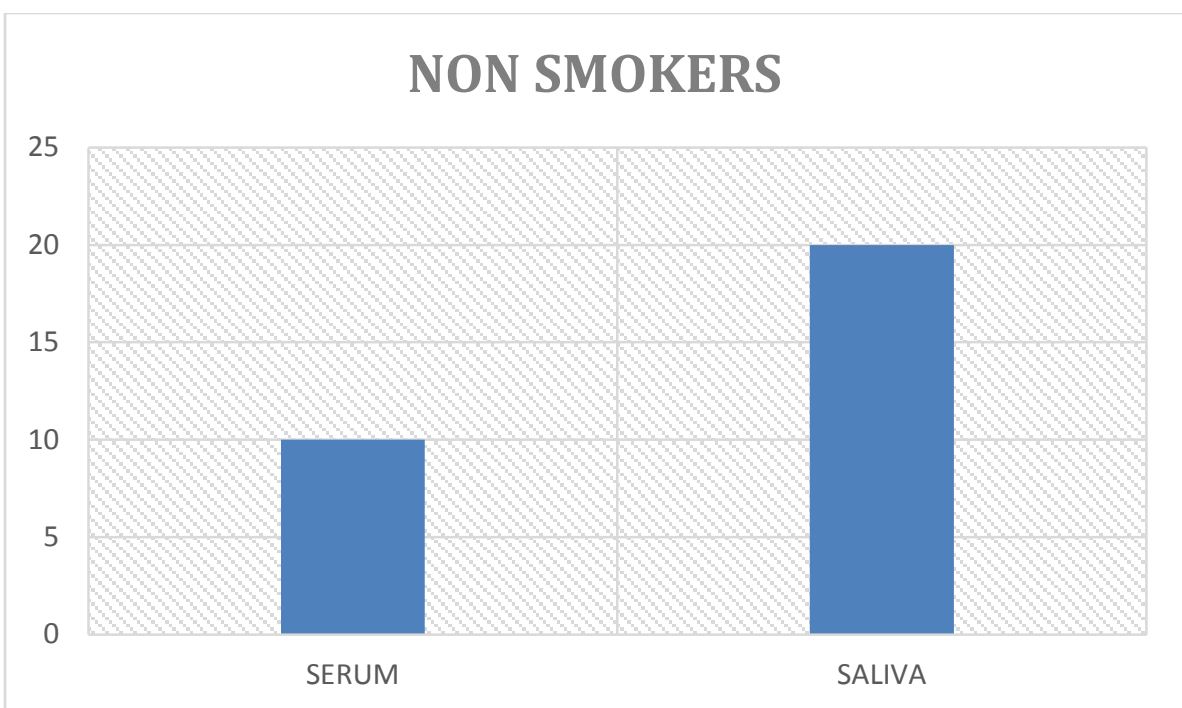

Fig 3:-Comparison of Serum and Saliva cotinine positive subjects in Nonsmokers

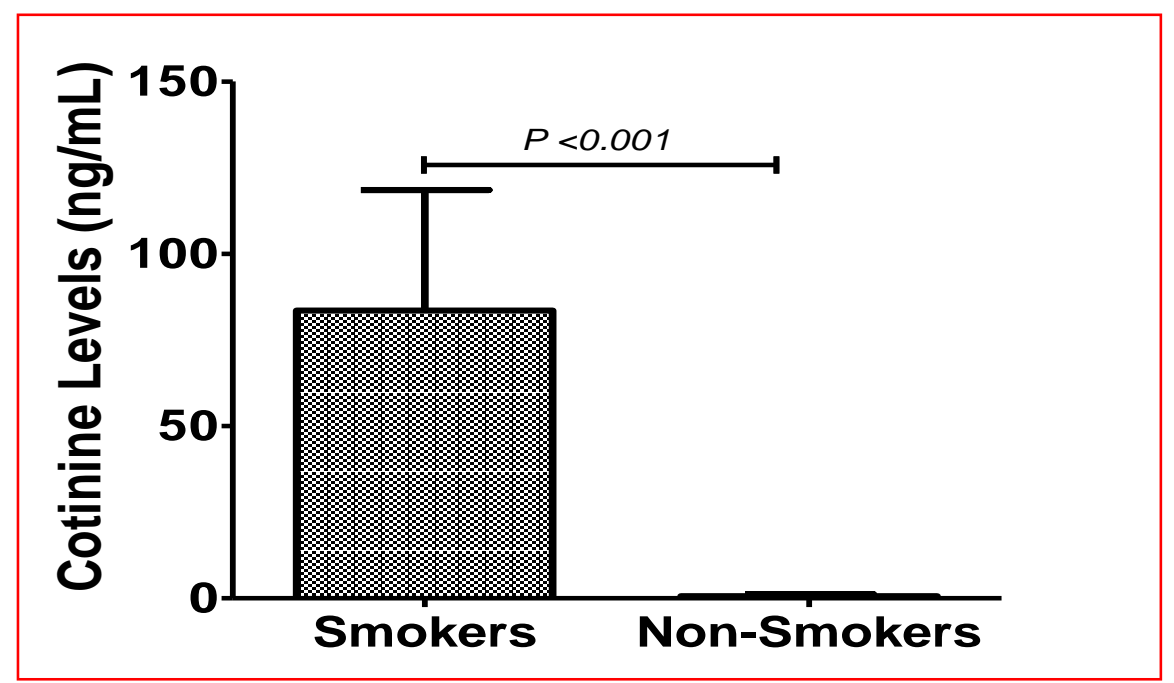

Fig 4:-Overall comparison of cotinine levels in Smokers and Non-Smokers

\section{Discussion:-}

Tobacco smoking accounts for $70 \%$ of chronic lung diseases (Johnson NW et al., 2000). Furthermore, in passive smokers, tobacco smoke which they inhale accounts for formation of free radicals and many toxic substances and the concentration of these harmful substances in passive smoking is relatively greater than in the smoke inhaled by a smoker which many people are not aware of. (Dvorak RD et al., 2008).

During epidemiological surveys and patient education, exposure of tobacco smoke was mostly evaluated via a selfadministered questionnaire (Malgorzata HJ et al., 2012; Etter JF et al., 2001). Since, self-administered questionnaire is not a good assessment for the exposure of smoke, quantitative assessment of metabolites of tobacco smoke exposure would help. Cotinine with its high specificity and retention period in the body fluids in sufficient quantifiable levels it is more preferred for quantifying tobacco smoke exposure (Watts RR et al., 1990). Cotinine, because of its longer half-life and higher specificity in separating smokers from nonsmokers as well as in evaluating day to day smoking behavior is considered as the best biomarker (Chadwick CA et al., 2007). Cotinine is found in higher quantity in non-ionized form in the blood ( $\mathrm{pH}$ 7.4) due to its $\mathrm{pKa}(4.5)$, and poor solubility of the free base form in lipids resulting in lower distribution to tissues, which can explain their extended half-life in blood. Another factor that prolongs cotinine half-life is relative low rate of renal excretion than nicotine (Feyerabend C et al 1980). Cotinine concentrations in saliva remains stationary even after several hours due to selective accumulation of 
cotinine by the salivary glands (Sepkovic DW et al., 1985). A study done by Wall AM et al., 1988 on cotinine in the serum, saliva and urine among active smokers, passive smokers and nonsmokers showed that cotinine can be estimated from all body fluids could distinguish active smokers from other groups.

Tobacco smoke exposure is classically recognized as a most important environmental hazard for periodontal diseases (Arbes SJ et al., 2001). The specific association between smoking and periodontitis is evident from the environmental studies (Brut B, 2005; Johnson N et al., 2000).

A study conducted by Bernert et al., 2000, showed that the unstimulated salivary cotinine levels are more closely correlated to serum cotinine levels than with stimulated saliva. Whole unstimulated saliva more advantageous as it enables collection of large sample volume and minimizes the influence of substances used to collect. It can also be assayed for multiple markers and allows unused sample to be frozen in an archive for future assay (Granger DA et al., 2007). Hence, unstimulated salivary cotinine levels were assessed and compared to serum cotinine levels in the current study.

In our study, smokers have shown cotinine positive levels in both serum (96\%) and saliva (100\%) and in nonsmokers, serum samples $(40 \%)$ and 20 saliva samples $(80 \%)$. The values of cotinine levels showed a significant difference $(p<0.001)$ among smokers and nonsmokers. Salivary cotinine levels were shown more positive than serum in both groups. This indicates that minor exposure to tobacco smoke can be detected in saliva samples.

In our study, among nonsmokers, 2 female subjects and 18 male subjects showed cotinine positivity in saliva samples, who have been exposed to passive tobacco smoke due to smoking habit of family members/work place. ETS cause pregnant women have an increased risk of having low-birth weight babies, increased risk of breast cancer $\&$ pneumonia etc. The passive exposure to tobacco smoke can significantly increase oxidative stress parameters and young people who are exposed to environmental tobacco smoke are often not aware of the fact that frequent passive exposure may lead to significant increase in cancer risk. An investigation done by Etter JF et al.,2000 on salivary cotinine levels showed 1.5 times higher concentration in nonsmokers whose close friends/spouses were smokers.

\section{Conclusion:-}

In the present study we identified increased cotinine positivity for saliva than serum. Among passive smokers, salivary cotinine showed higher positivity than serum cotinine. Further cross sectional studies has to be done by using larger sample size. Though, chromatographic methods are more specific for evaluation, due to its expenses and availability, salivary cotinine estimation by ELISA can be used in epidemiological surveys as patient education and assessment tool for tobacco smoke exposure.

\section{Acknowledgement:-}

We are thankful to Mr.T.Praveen for his valuable support in manuscript preparation.

\section{References:-}

1. Al-Delaimy, W. K. (2002). Hair as a biomarker for exposure to tobacco smoke. Tobacco Control, 11(3), 176182 .

2. ArbesJr, S. J., Agustsdottir, H., \& Slade, G. D. (2001). Environmental tobacco smoke and periodontal disease in the United States. American Journal of Public Health, 91(2), 253.

3. Avila-Tang, E., Al-Delaimy, W. K., Ashley, D. L., Benowitz, N., Bernert, J. T., Kim, S., \& Hecht, S. S. (2012). Assessing secondhand smoke using biological markers. Tobacco control, tobaccocontrol-2011.

4. Benkirane, S., Nicolas, A., Galteau, M. M., \&Siest, G. (1991). Highly sensitive immuno-assays for the determination of cotinine in serum and saliva. Comparison between RIA and an avidin-biotin ELISA. Clinical Chemistry and Laboratory Medicine, 29(6), 405-410.

5. Benowitz, N. L. (1996). Cotinine as a biomarker of environmental tobacco smoke exposure. Epidemiologic reviews, 18(2), 188-204.

6. Benowitz, N. L., Hukkanen, J., \& Jacob III, P. (2009). Nicotine chemistry, metabolism, kinetics and biomarkers. In Nicotine psychopharmacology (pp. 29-60). Springer Berlin Heidelberg.

7. Benowitz, N. L., Bernert, J. T., Caraballo, R. S., Holiday, D. B., \& Wang, J. (2008). Optimal serum cotinine levels for distinguishing cigarette smokers and nonsmokers within different racial/ethnic groups in the United States between 1999 and 2004. American journal of epidemiology, 169(2), 236-248. 
8. BernertJr, J. T., McGuffey, J. E., Morrison, M. A., \&Pirkle, J. L. (2000). Comparison of serum and salivary cotinine measurements by a sensitive high-performance liquid chromatography-tandem mass spectrometry method as an indicator of exposure to tobacco smoke among smokers and nonsmokers. Journal of analytical toxicology, 24(5), 333-339.

9. Burt B, Research, Science and Therapy Committee of the American Academy of Periodontology. Position paper: epidemiology of periodontal diseases. J Periodontol. 2005 Aug;76(8):1406-19.

10. Chadwick, C. A., \&Keevil, B. (2007). Measurement of cotinine in urine by liquid chromatography tandem mass spectrometry. Annals of clinical biochemistry, 44(5), 455-462.

11. Chiappin, S., Antonelli, G., Gatti, R., \&Elio, F. (2007). Saliva specimen: a new laboratory tool for diagnostic and basic investigation. Clinicachimicaacta, 383(1), 30-40.

12. Dvorak, R. D., \& Simons, J. S. (2008). Affective differences among daily tobacco users, occasional users, and non-users. Addictive behaviors, 33(1), 211-216.

13. Etter, J. F., Due, T. V., \&Perneger, T. V. (2000). Saliva cotinine levels in smokers and nonsmokers. American Journal of Epidemiology, 151(3), 251-258.

14. Etter, J. F., \&Perneger, T. V. (2001). Measurement of self reported active exposure to cigarette smoke. Journal of Epidemiology \& Community Health, 55(9), 674-680.

15. Feyerabend, C., \& Russell, M. A. H. (1980). Rapid gas-liquid chromatographic determination of cotinine in biological fluids. Analyst, 105(1255), 998-1001.

16. Florescu, A., Ferrence, R., Einarson, T., Selby, P., Soldin, O., \&Koren, G. (2009). Methods for quantification of exposure to cigarette smoking and environmental tobacco smoke: focus on developmental toxicology. Therapeutic drug monitoring, 31(1),14.

17. Gonzalez, Y. M., De Nardin, A., Grossi, S. G., Machtei, E. E., Genco, R. J., \& De Nardin, E. (1996). Serum cotinine levels, smoking, and periodontal attachment loss. Journal of dental research, 75(2), 796-802.

18. Granger, D. A., Johnson, S. B., Szanton, S. L., Out, D., \& Schumann, L. L. (2012). Incorporating salivary biomarkers into nursing research: an overview and review of best practices. Biological research for nursing, 14(4), 347-356.

19. Granger, D. A., Kivlighan, K. T., Fortunato, C., Harmon, A. G., Hibel, L. C., Schwartz, E. B., \&Whembolua, G. L. (2007). Integration of salivary biomarkers into developmental and behaviorally-oriented research: problems and solutions for collecting specimens. Physiology \& behavior, 92(4), 583-590.

20. Haley, N. J., Axelrad, C. M., \& Tilton, K. A. (1983). Validation of self-reported smoking behavior: biochemical analyses of cotinine and thiocyanate. American Journal of Public Health, 73(10), 1204-1207.

21. Jacob, P., Yu, L., Duan, M., Ramos, L., Yturralde, O., \&Benowitz, N. L. (2011). Determination of the nicotine metabolites cotinine and trans-3'-hydroxycotinine in biologic fluids of smokers and non-smokers using liquid chromatography-tandem mass spectrometry: biomarkers for tobacco smoke exposure and for phenotyping cytochrome P450 2A6 activity. Journal of Chromatography B, 879(3), 267-276.

22. Jarvis, M. J., Russell, M. A., Benowitz, N. L., \&Feyerabend, C. O. L. I. N. (1988). Elimination of cotinine from body fluids: implications for noninvasive measurement of tobacco smoke exposure. American journal of public health, 78(6), 696-698.

23. Johnson, N., \& Bain, C. (2000). Tobacco and oral disease. British Dental Journal, 189(4).

24. Kunzle, R., Mueller, M. D., Hanggi, W., Birkhauser, M. H., Drescher, H., \&Bersinger, N. A. (2003). Semen quality of male smokers and nonsmokers in infertile couples. Fertility and sterility, 79(2), 287-291.

25. Kyerematen, G. A., Morgan, M. L., Chattopadhyay, B., Bethizy, J. D., \&Vesell, E. S. (1990). Disposition of nicotine and eight metabolites in smokers and nonsmokers: identification in smokers of two metabolites that are longer lived than cotinine. Clinical Pharmacology \& Therapeutics, 48(6), 641-651.

26. Malafatti, L., Maia, P. P., Martins, M. C. G., Siqueira, M. E. P. B. D., \& Martins, I. (2010). Single gas chromatography method with nitrogen phosphorus detector for urinary cotinine determination in passive and active smokers. Brazilian Journal of Pharmaceutical Sciences, 46(4), 769-776.

27. Martinez-Donate, A. P., Hovell, M. F., Hofstetter, C. R., Gonzalez-Perez, G. J., Adams, M. A., Sanchez, J. D. J., \& Guzman-Cerda, G. (2005). Smoking, exposure to secondhand smoke, and smoking restrictions in Tijuana, Mexico. RevistaPanamericana de SaludPública, 18(6), 412-417.

28. Matsumoto, A., Ino, T., Ohta, M., Otani, T., Hanada, S., Sakuraoka, A., \& Hara, M. (2010). Enzyme-linked immunosorbent assay of nicotine metabolites. Environmental health and preventive medicine, 15(4), $211-216$.

29. Nosratzehi, T., Arbabi-Kalati, F., Alijani, E., \&Tajdari, H. (2015). Comparison of Cotinine Salivary Levels in Hookah Smokers, Passive Smokers, and Non-Smokers. Addiction \& health, 7(3-4), 184.

30. Salimetrics, L. L. C., \&SalivaBio, L. L. C. (2011). Saliva collection and handling advice. Available oat www. Salimetrics. Com. Accessed 1. 
31. Sepkovic, D. W., \& Haley, N. J. (1985). Biomedical applications of cotinine quantitation in smoking related research. American journal of public health, 75(6), 663-665.

32. Sikorska-Jaroszynska, M. H., Mielnik-Blaszczak, M., Krawczyk, D., Nasilowska-Barud, A., \&Blaszczak, J. (2012). Passive smoking as an environmental health risk factor. Annals of Agricultural and Environmental Medicine, 19(3).

33. Stanley, S. D., Gairola, C. G., Diana, J., Huffman, M., Sadove, R., Woods, W. E., \& Tobin, T. (1993). Development and characterization of an ELISA for cotinine in biological fluids. Inhalation toxicology, 5(4), 403-413.

34. Szumska, M., Tyrpień, K., Kowalska, M., Wielkoszyński, T., \&Dobosz, C. (2013). Medicine students and exposure to environmental tobacco smoke. International journal of occupational medicine and environmental health, 26(2), 313-320.

35. Vine, M. F., Hulka, B. S., Margolin, B. H., Truong, Y. K., Hu, P. C., Schramm, M. M., ... \& Everson, R. B. (1993). Cotinine concentrations in semen, urine, and blood of smokers and nonsmokers. American Journal of Public Health, 83(9), 1335-1338.

36. Voller, A., Bartlett, A., \& Bidwell, D. E. (1978). Enzyme immunoassays with special reference to ELISA techniques. Journal of Clinical Pathology, 31(6), 507-520.

37. Wall, M. A., Johnson, J., Jacob, P., \&Benowitz, N. L. (1988). Cotinine in the serum, saliva, and urine of nonsmokers, passive smokers, and active smokers. American Journal of Public Health, 78(6), 699-701.

38. Watts, R. R., Langone, J. J., Knight, G. J., \&Lewtas, J. (1990). Cotinine analytical workshop report: consideration of analytical methods for determining cotinine in human body fluids as a measure of passive exposure to tobacco smoke. Environmental Health Perspectives, 84, 173.

39. Wie, S. I., Andrews, R. E., Hammock, B. D., Faust, R. M., \& Bulla, L. A. (1982). Enzyme-linked immunosorbent assays for detection and quantitation of the entomocidalparasporal crystalline protein of Bacillus thuringiensissubspp. Kurstaki and israelensis. Applied and environmental microbiology, 43(4), 891894. 